\title{
Effectiveness of oral health education on 8- to 10-year-old school children in rural areas of the Magway Region, Myanmar
}

\author{
Kyu Kyu Swe ${ }^{1 *}$, Aung Kyaw Soe ${ }^{2}$, Saw Htun Aung ${ }^{3}$ and Htin Zaw Soe ${ }^{4}$
}

\begin{abstract}
Background: Oral diseases are common and widespread around the world. The most common oral diseases are preventable, and early onset is reversible. Myanmar faces many challenges in rendering oral health services, because approximately $70 \%$ of the total population resides in rural areas. These relate to the availability and accessibility of oral health services. Therefore, oral health education is one key element to prevent oral diseases and to promote oral health.

Methods: A quasi-experimental study was carried out at Basic Education Middle Schools in rural areas of Magway Township to study the effectiveness of oral health education on the knowledge and behavior of 8- to 10-year-old school children. A total of 220 school children, 110 from intervention schools and 110 from control schools, participated in this study from 2015 to 2017. Data were collected before and after intervention in the two groups by using a self-administered questionnaire. Tooth brushing method data were collected by direct observation with a checklist. Oral health education was provided at eight weekly intervals for 1 year. At one and a half years, third-time data collection was done on the intervention group to assess retention. Chi-square test, two samples $t$-test and one-way repeated measure ANOVA were used for data analysis. The study was approved by the Institutional Review Board of the University of Public Health in Yangon, Myanmar.
\end{abstract}

Results: There were significant differences between the two groups in four out of five knowledge questions $(p<0.05)$ and all behavior questions $(p<0.001)$ after intervention. A positive effect of oral health education for a period of $45 \mathrm{~min}$ at eight weekly intervals for 1 year was found in the intervention group. The intervention had a significant effect on the sustainability of the correct knowledge and behavior of the intervention group although the education session was stopped for 6 months $(p<0.001)$. Their mean knowledge and behavioral scores at three different points in time were $(2.45 \pm 1.12$ and $1.56 \pm 0.90)$ at baseline, ( $3.79 \pm 1.12$ and $3.60 \pm 1.21)$ at 1 year after education and $(4.07 \pm 0.98$ and $3.24 \pm 1.31)$ at 6 months after cessation of education, respectively.

Conclusions: Repeated oral health education was effective in promoting and sustaining oral health knowledge and behavior.

Keywords: Oral health education, Oral health knowledge and behavior

*Correspondence: kyuswe@gmail.com

1 Department of Preventive and Social Medicine, Uiversity of Medicine,

Magway, Myanmar

Full list of author information is available at the end of the article

\begin{abstract}
Introduction
Dental caries, periodontal diseases, and oral cancers are common and affect men, women, and children. Over 3.5 billion people suffer from oral diseases which continued to threaten the health, well-being, the social and economic productivity of millions of people throughout
\end{abstract}


the developing world. Oral diseases are becoming global issues and should be considered as public health importance [1]. Many behavioral and social characteristics like eating habits, oral health knowledge, practices, availability, and accessibility of oral health services are some of the issues concerning oral health. Behavioral interventions or education to the individual about how to maintain the pleasant condition of a person's mouth or how to control the mental and social problems that affect the dental health behavior are required to reduce the oral health problems and to promote oral health [2]. Personal habits like poor oral hygiene, smoking, alcohol drinking, and eating an unhealthy diet are modifiable risk factors that affect the health of gum. Periodontal disease is one of the common oral diseases and can be prevented by maintaining the individual's good oral health behavior like tooth cleaning with a toothbrush and toothpaste, inter-dental cleaning with dental floss, and other oral hygiene measures [3]. Health education activities have a powerful effect on the behavioral characteristics of the individual like oral health knowledge, attitude, practice, eating habits, tooth decay, periodontal health, and oral hygiene [4]. It is estimated that common oral diseases such as tooth decay and gum diseases affect nearly $80 \%$ of children who are at school-going age across the globe [5]. As the lifestyle and behavioral patterns of the people are changing rapidly, these become favorable to the onset of oral diseases. Oral diseases are linked by common preventable risk factors including eating a lot of sweet food, excessive use of tobacco, high alcohol intake [5]. In Myanmar, knowledge, attitudes and practices on oral health among rural populations were low [6], and oral health status among 5-yearand 12-year- old children was not satisfactory [7]. Dental public health care services are required more than before to reduce the high level of dental caries of the 12-13-year age group in Myanmar [8]. Three-month oral health education had a positive effect on the total knowledge, attitude, and practice (KAP) scores and also plaque scores of the study group of 12-year-old Myanmar school children [9]. It is estimated that the dentist-to-population ratio in Myanmar is 1:16,000 and the dental professions are taking the responsibility to give oral health care to the whole population [10]. Besides, there are no dental therapists and dental hygienists. Hence, the Myanmar population has a low opportunity to take sufficient oral health education because of an inadequate dentist population ratio [10]. To assess the magnitude of the preventive task, it is necessary to know the oral health situation of school children. Approximately $70 \%$ of the total population in Myanmar resides in rural areas. These relate to the availability and accessibility of oral health services, and as a consequence, this may have a challenge in rendering oral health services throughout the country. Therefore, oral health education plays a pivotal role in solving oral health problems, preventing common oral diseases, and promoting the oral health of the rural population. The World Health Organization suggested that school oral health promotion activities are effective in preventing oral diseases and promoting oral health among school children [4]. In Myanmar, oral health education programs are implemented and oral health services are provided to school children yearly by a dental surgeon as part of the functions of the school health team, however, these oral health programs are not strengthened [10]. Children aged 8-10 years among school children are suitable for identifying oral health situation and for providing primary prevention because they have mixed dentition, both primary teeth and permanent teeth. Hence, the current study was planned to obtain updated information on the oral health situation of school children in Myanmar and supported the role of educational programs in promoting oral health and preventing common oral diseases at an early stage in children. Furthermore, this study was an important foundation to stimulate the development of oral health awareness among the community.

\section{Methods}

\section{Study design, area, population and period}

A quasi-experimental nonequivalent control group study design was carried out in two randomly selected Basic Education Middle Schools (BEMSs) in a rural area of Magway Township from 2015 to 2017 to determine the effectiveness of oral health education on oral health knowledge and behavior of 8- to 10-year-old school children. A total of 220 school children, 110 from intervention school and 110 from control school, participated in this study. 8- to 10-year-old healthy children who were attending the selected middle schools were included, and those who were unwilling to participate in the study and not present on the day of data collection were excluded.

\section{Sample size and sampling procedure}

The sample size was calculated by $\mathrm{n}=\left(\mathrm{z}_{\alpha}+\mathrm{z}_{1}\right.$. $\beta)^{2} \quad\left(\mathrm{p}_{\mathrm{c}} \quad \mathrm{q}_{\mathrm{c}}+\mathrm{p}_{\mathrm{e}} \quad \mathrm{q}_{\mathrm{e}}\right) \quad / \mathrm{d}^{2}+2 / \mathrm{d}+2=(1.96+1.0364)^{2}$ $(0.47 \times 0.53+0.69 \times 0.31) /(0.22)^{2}+2 /(0.22)+2$ with $85 \%$ power and $5 \%$ type one error rate. A drop-out rate of $10 \%$ for each group was considered. The hypothesized proportions of twice-daily tooth brushing practice after lecturing in the control group and intervention groups were $47 \%$ and $69 \%$, respectively [11]. The sample size for each group was 110 and the total sample size was 220. Prior to conducting the study, permission was obtained from the Township Educational Officer and Township Medical Officer. Out of a total of 47 BEMSs in Magway Township, there were only four in urban areas. To obtain the required sample, in the first stage, two BEMSs from rural 
areas and in the second stage, 110 students from each school, were randomly selected.

\section{Data collection method}

The research question was developed by the author based on the inputs obtained from various scientific articles and face validation was done by an independent subject expert not involved in the study following which the content validity was assessed by three experienced pediatric dental specialists in the field. A pilot survey was conducted on 30 students of the same age in one of the schools in the study area and revised it, as suggested. Attention was paid to ensure the clarity of interpretation, choice of words, and meaningfulness of the questionnaire in order to be easily apprehended by children of this age. A reliability analysis was carried out and cronbach's alpha was 0.75 . It comprised of five knowledge and five behavioral questions. The outcome was reported as correct/incorrect response to knowledge questions and proper/improper response to behavior questions. Oral health education (OHE) was given to the intervention group only at eight weekly intervals for 1 year. An oral health education session for a period of approximately 45 min was prepared on key oral health messages, such as the structure and functions of teeth, types of dentition, causes and prevention of common oral diseases, importance of brushing teeth twice daily, proper tooth brushing technique, importance of regular dental visits. Chalk and blackboard, dent form model, charts, toothbrush and toothpaste were used as oral health education aids. The proper tooth brushing technique (modified bass technique) was demonstrated on a dent form model. After completion of the whole study, an oral health education session was also conducted for the children in the control group. A visit was paid to each school before data collection to discuss the research procedure with the school headmaster, and written informed consent was obtained from the caregivers. At the beginning of the study, the baseline data were collected in both groups by using a self-administered questionnaire except for one behavioral question that is the 'method of tooth brushing. It was collected by direct observation with a checklist. The questionnaires, originally constructed in English and translated into Burmese (Myanmar language), were given and completed by the children under the supervision of the research team members with the help of class teachers to ensure that all questions were answered. Interpersonal communications were not allowed during answering. After a 1-year period from the collection of the baseline data, post-intervention data were collected in the two groups using the same questionnaire as at baseline. After 1 year and 6 months, retention of proper knowledge and behavior were determined in the intervention group only. Toothbrush and toothpaste were provided to all participant children in both groups before and after the intervention. The scoring system and operational definitions are shown in 'Additional file 1: Table S1', 'Additional file 1: Table S2' and 'Additional file 1: Table S3'.

\section{Data management and analysis}

The data were checked for completeness and consistency daily and analyzed by using SPSS version 16.0. Descriptive statistics were computed for all variables. Differences between intervention and control groups responded to the knowledge and behavior questions by correct answers before and after intervention were calculated. The net effect of the intervention program was estimated by subtracting the percentage change pre- to post-intervention in control students from that for the intervention students. One-way repeated measure ANOVA with Bonferroni correction (post hoc test) was used to determine the retention of proper knowledge and behavior on oral health at three different points in time, at baseline, at 1 year after OHE, at 6 months after cessation of OHE, in students who received OHE at eight weekly intervals for 1 year. The level of statistical significance for all tests was set at 0.05 .

\section{Results}

Table 1 shows the demographic characteristics of the school children in the two groups at baseline and 1 year after oral health education. The age distribution from 8 to 10 years before and after intervention was $19.1 \%, 58.2 \%$, and $22.7 \%$ in the intervention group and $14.6 \%, 20.9 \%$, and $64.5 \%$ in the control group, respectively. According to the gender, boy and girl distribution before and after intervention were $43.6 \%$ and $56.4 \%$ in the intervention group and $51.8 \%$ and $48.2 \%$ in the control group, respectively. Table 2 shows correct knowledge and proper behavior on oral health among school children between the two groups. In the intervention group, the correct proportion was higher

\begin{tabular}{|c|c|c|c|}
\hline Variables & Categories & $\begin{array}{l}\text { Intervention group } \\
\mathrm{n}(\%)\end{array}$ & $\begin{array}{l}\text { Control group } \\
\text { n (\%) }\end{array}$ \\
\hline \multirow[t]{3}{*}{ Age (year) } & 8 & 21(19.1) & $16(14.6)$ \\
\hline & 9 & $64(58.2)$ & $23(20.9)$ \\
\hline & 10 & $25(22.7)$ & $71(64.5)$ \\
\hline \multirow[t]{2}{*}{ Gender } & Boy & $48(43.6)$ & $57(51.8)$ \\
\hline & Girl & $62(56.4)$ & $53(48.2)$ \\
\hline
\end{tabular}


Table 2 Correct knowledge and proper behavior on oral health between the two groups

\begin{tabular}{|c|c|c|c|c|}
\hline Variables & Categories & $\begin{array}{l}\text { Intervention } \\
\text { n (\%) }\end{array}$ & $\begin{array}{l}\text { Control } \\
\text { n (\%) }\end{array}$ & $p$ value \\
\hline \multicolumn{5}{|l|}{ Knowledge questions } \\
\hline \multirow[t]{2}{*}{ The main cause of tooth decay } & At baseline & $17(15.5)$ & $13(11.8)$ & 0.432 \\
\hline & After 1 year & $79(71.8)$ & $20(18.2)$ & $<0.001$ \\
\hline \multirow[t]{2}{*}{ The main cause of gum diseases } & At baseline & $29(26.4)$ & $64(58.2)$ & $<0.001$ \\
\hline & After 1 year & $60(54.5)$ & $41(37.3)$ & 0.010 \\
\hline \multirow[t]{2}{*}{ Prevention of dental caries and periodontal diseases } & At baseline & $78(70.9)$ & $85(77.3)$ & 0.281 \\
\hline & After 1 year & $100(90.9)$ & $88(80.0)$ & 0.022 \\
\hline \multirow[t]{2}{*}{ Foods that can cause dental caries } & At baseline & $71(64.5)$ & $72(65.5)$ & 0.888 \\
\hline & After 1 year & $82(74.5)$ & $71(64.5)$ & 0.107 \\
\hline \multirow[t]{2}{*}{ Development of oral cancer } & At baseline & $74(67.3)$ & $84(76.4)$ & 0.134 \\
\hline & After 1 year & $96(87.3)$ & $82(74.5)$ & 0.016 \\
\hline \multicolumn{5}{|l|}{ Behavior questions } \\
\hline \multirow[t]{2}{*}{ Frequency of tooth brushing } & At baseline & $39(35.5)$ & $25(22.7)$ & 0.038 \\
\hline & After 1 year & $74(67.3)$ & $7(6.4)$ & $<0.001$ \\
\hline \multirow[t]{2}{*}{ Occasion of tooth brushing } & At baseline & $21(19.1)$ & $8(7.3)$ & 0.010 \\
\hline & After 1 year & $70(63.6)$ & $4(3.6)$ & $<0.001$ \\
\hline \multirow[t]{2}{*}{ Devices using in tooth brushing } & At baseline & $99(90.0)$ & $92(83.6)$ & 0.163 \\
\hline & After 1 year & $106(96.4)$ & $84(76.4)$ & $<0.001$ \\
\hline \multirow[t]{2}{*}{ Device used to remove food debris stuck between the teeth } & At baseline & $8(7.3)$ & $5(4.5)$ & 0.391 \\
\hline & After 1 year & $51(46.4)$ & $4(3.6)$ & $<0.001$ \\
\hline \multirow[t]{2}{*}{ Pattern of tooth brushing (by direct observation) } & At baseline & $5(4.5)$ & $3(2.7)$ & 0.721 \\
\hline & After 1 year & 95(86.4) & $6(5.5)$ & $<0.001$ \\
\hline
\end{tabular}

after intervention than before regarding all knowledge questions, and in the control group, the correct response rates before and after intervention were nearly the same except for the main cause of tooth decay and gum diseases. In comparing the two groups before intervention, approximately $16 \%$ of intervention students and $12 \%$ of control students gave the true answer with regard to the main cause of tooth decay. The majority of school children in both groups gave the true answer with regard to behavior about devices used in tooth brushing before as well as after intervention. Before intervention, approximately $7 \%$ of school children in the intervention group and nearly $5 \%$ of school children in the control group used dental floss to remove food debris stuck between the teeth. Regarding the pattern of tooth brushing, nearly $5 \%$ in the intervention group and only $3 \%$ in the control group brushed their teeth according to the recommended method. Before intervention, no significant differences were found between the two groups in four out of five knowledge questions and in three out of five behavior questions $(p>0.05)$. These were knowledge about the main cause of gum diseases and behavior regarding the frequency and occasion of tooth brushing $(p<0.05)$. After intervention, significant differences were found between the two groups in four out of five knowledge questions and in all behavior questions $(p<0.05)$. The only knowledge question that showed no significant differences between the two groups was 'foods that can cause dental caries' $(p>0.05)$. Table 3 shows percentage changes in response to knowledge and behavior on oral health before and after intervention between the two groups, and a positive effect of oral health education for a period of $45 \mathrm{~min}$ at eight weekly intervals for 1 year was noted. Table 4 shows the mean knowledge and behavior scores on oral health in the intervention group only. There were $2.45 \pm 1.12,3.79 \pm 1.12$, and $4.07 \pm 0.98$ and $1.56 \pm 0.90,3.60 \pm 1.21$, and $3.24 \pm 1.31$ at baseline, 1 year after OHE and 6 months after cessation of OHE, respectively. A statistically significant effect of eight weekly intervals for 1-year OHE was found on total knowledge and behavior scores in the intervention group $(p<0.001)$. Table 5 shows highly significant differences between two different points in time (baseline vs 1 year after OHE and baseline vs 6 months after cessation of OHE) regarding total knowledge and behavior scores $(p<0.001)$ and no significant difference between 1 year after OHE and 6 months after cessation of OHE $(p=0.159)$ in knowledge and $(p=0.060)$ in behavior. It was shown that 
Table 3 Percentage change in responses to knowledge and behavior on oral health among the school children in both groups before and after intervention

\begin{tabular}{|c|c|c|c|}
\hline \multirow[t]{2}{*}{ Knowledge and behavior questions on oral health } & \multicolumn{2}{|c|}{$\begin{array}{l}\% \text { Difference between before and } \\
\text { after intervention }\end{array}$} & \multirow{2}{*}{$\begin{array}{l}\text { Net effect } \\
\text { of intervention (\% } \\
\text { change) }\end{array}$} \\
\hline & Intervention & Control & \\
\hline \multicolumn{4}{|l|}{ Knowledge questions } \\
\hline The main cause of tooth decay & +56.37 & +6.36 & +50.01 \\
\hline The main cause of gum diseases & +28.19 & -20.91 & +49.1 \\
\hline Prevention of dental caries and periodontal diseases & +20 & +2.73 & +17.27 \\
\hline Foods that can cause dental caries & +10 & -0.9 & +10.9 \\
\hline Development of oral cancer & +20 & -1.81 & +21.81 \\
\hline \multicolumn{4}{|l|}{ Behavior questions } \\
\hline Frequency of tooth brushing & +31.82 & -10.91 & +42.73 \\
\hline Occasion of tooth brushing & +44.55 & -3.63 & +48.18 \\
\hline Devices using in tooth brushing & +6.36 & -7.28 & +13.64 \\
\hline Device used to remove food debris stuck between the teeth & +39.09 & -0.91 & +40.00 \\
\hline Pattern of tooth brushing (by direct observation) & +81.81 & +2.72 & +79.09 \\
\hline
\end{tabular}

Table 4 Oral health scores at three different points in time in the intervention group $(n=110)$

\begin{tabular}{llll}
\hline Variables & Categories & Mean \pm SD & $\boldsymbol{p}$ value \\
\hline Knowledge scores & At baseline & $2.45 \pm 1.12$ & $<0.001$ \\
& At 1 year & $3.79 \pm 1.12$ & \\
& At one and a half years & $4.07 \pm 0.98$ & \\
Behavior scores & At baseline & $1.56 \pm 0.90$ & $<0.001$ \\
& At 1 year & $3.60 \pm 1.21$ & \\
& At one and a half years & $3.24 \pm 1.31$ &
\end{tabular}

$\mathrm{SD}$, standard deviation

the school children in the intervention group had the ability to maintain the correct knowledge and behavior related to oral health even though the OHE session was stopped for 6 months.

\section{Discussion}

At the beginning of the study, the minimum age of the school children in both groups was 8 years and the maximum age was 10 years. The duration of the study lasted for one and a half years. There was no attrition in either group after intervention. On the other hand, some oral health intervention studies reported that there was dropout of the participants when assessing the effect of OHE on oral health knowledge and behavior in Wuhan City of China [12], Tehran of Iran [13], and Riyadh of Saudi Arabia [14] which are a contrast to the findings of the present study. The result of China documented that the drop-out rate is a small amount and there is no problem in assessing the outcomes [12]. The correct response rates were more or less the same between the two groups before intervention in almost all of the knowledge questions $(p>0.05)$ except one question concerning the main cause of gum diseases, in which the correct answer rate of control students was significantly greater than that of

Table 5 Retention of oral health knowledge and behavior in the intervention group $(n=110)$

\begin{tabular}{|c|c|c|c|c|c|}
\hline \multirow[t]{2}{*}{ Variables } & \multirow[t]{2}{*}{ Categories } & \multirow{2}{*}{$\begin{array}{l}\text { Mean } \\
\text { diff }\end{array}$} & \multicolumn{2}{|c|}{$95 \% \mathrm{Cl}$ for diff } & \multirow[t]{2}{*}{$p$ value } \\
\hline & & & Lower & Upper & \\
\hline \multirow[t]{3}{*}{ Knowledge scores } & Baseline vs 1 year & -1.345 & -1.69 & -1.00 & $<0.001$ \\
\hline & 1 year vs one and a half years & -0.282 & -0.63 & 0.07 & 0.159 \\
\hline & Baseline vs one and a half years & -1.627 & -1.98 & -1.28 & $<0.001$ \\
\hline \multicolumn{6}{|l|}{ Behavior scores } \\
\hline & Baseline vs 1 year & -2.04 & -2.41 & -1.67 & $<0.001$ \\
\hline & 1 year vs one and a half years & 0.36 & -0.01 & 0.74 & 0.060 \\
\hline & Baseline vs one and a half years & -1.67 & -2.05 & -1.30 & $<0.001$ \\
\hline
\end{tabular}

diff, difference; $\mathrm{Cl}$, confidence interval; vs, versus 
intervention students $(p<0.001)$. It may be possible that even in the absence of health education, some children might have tried to search and obtain correct answers and gain knowledge through various sources, such as social media, TV, toothpaste advertisements, etc. After a 1-year intervention, significant differences were observed between the two groups in almost all knowledge questions $(p<0.05)$ except one question concerning foods that can cause dental caries $(p>0.05)$. This may be attributed to the school co-curriculum wherein some general information about the unhealthy effect of sweetened foods and drinks on teeth is taught to the school children in the primary classes. No significant differences were found between the two groups before OHE in three out of five behavioral questions $(p>0.05)$, and with regard to frequency and occasion of tooth brushing, significantly more of the students in the intervention group brushed their teeth twice per day and cleaned their teeth in the morning before breakfast and at night before going to bed compared with their control counterparts $(p<0.05)$. This might be due to unequal accessibility and availability of dental health services among the students. However, the proportion of correct behavior was significantly higher in all behavioral items for the intervention group following OHE $(p<0.001)$. This may be because of the methods applied and the materials used in the OHE session. The results of this study are seemed to reaffirm the findings of a study conducted with samples of 1661 female primary school children in Saudi Arabia who are from 6 to 8 years old to assess the effectiveness of oral health education intervention on oral health knowledge and behavior in which there was a significant improvement in all knowledge and behavior questions after intervention $(p<0.001)$ [14]. A study conducted in China to assess the effect of school-based OHE intervention on children, mothers and school teachers reported that children in the experimental group are more than those in the control group regarding the adoption of regular oral health behavior such as tooth brushing at least twice a day, dental visits annually, use of fluoride toothpaste and less frequent consumption of cakes/biscuits which supports the present study [12]. The present study is similar to one study in Bangladesh which showed that overall significant improvement was observed in almost all the indicators of knowledge and behavior after OHE compared to before $(p<0.001)$ [15]. When the present study assessed the percentage changes in response to knowledge and behavior on oral health before and after intervention between the two groups, a positive net effect of intervention was observed. The findings of the present study were in accordance with an intervention study conducted in Ireland wherein an oral health intervention for 6 weeks was performed among primary school children aged 7-12 years and positive changes were observed in oral health knowledge and behaviors [16]. Other studies performed in Chandigarh, Northern India [17], Tanzania [18] and Greece [19] reported that school-based OHE programs significantly improved knowledge and behavior. In a study performed in Kyauktan and Tharkayta Townships of the Yangon Region in Myanmar, significant improvement of knowledge, attitude and practice scores on oral hygiene was found between the baseline and 3 months after intervention among 12-year-old school children [9]. In India, a systematic review was conducted in a total of 40 articles to assess the effectiveness of oral health education programs on knowledge, attitude, practice and oral health status. In their review, they reported that oral health education was effective in improving knowledge on oral health in all studies; however, with regard to practice outcome, thirteen studies were found to be effective and two studies were not effective [20]. Another systematic review was conducted in a total of 18 articles to evaluate the effectiveness of school dental health education on oral health status, oral health-related knowledge and practice of 6 to 12-year-old children in which OHE had a positive impact on oral health status, knowledge and practice, such as frequency and duration of brushing, use of fluoride toothpaste [21]. These disparities might be due to differences in the target age group, methods and duration of the oral health education program and background characteristics of the study subjects. The present study showed that the eight weekly oral health educations for 1 year had a statistically significant effect on total knowledge and behavior scores of the oral health among the school children in the intervention group even though stopping of the education program for 6 months after 1-year OHE, and it was found that the students in the intervention group had sustainability on positive knowledge and behavior $(p<0.001)$. Similar to the present study, a study performed in India documented that reinforcement through repeated $\mathrm{OHE}$ sessions in the intervention schools resulted in significant improvement of oral health knowledge and practice even after cessation of the program [22]. Another study performed in northwest England reported that schools with more frequent exposures to the program had better scores than schools with fewer exposures [23]. A study in Karachi of Pakistan showed that one-time teacher-led OHE was ineffective compared to repeated and reinforced OHE in improving oral health knowledge, behavior and oral hygiene status [24]. Hence, it can be suggested that OHE is a feasible way to reach out to all sections of the children whether rich or poor, near or far, developed or underdeveloped. The provision of OHE services improves the oral health of the students which will be passed on to their family members and neighboring 
community and has had an effect on the whole community of the country. The results of this study can be generalized to school children in Myanmar because schools and students are randomly selected in collecting the data for measuring the outcome variables. However, the study procedure had some limitations. Teachers and caregivers were not included in the OHE sessions, which might have affected the effectiveness of OHE since they have daily contact with the students and may be essential for the achievement of long-term benefits.

\section{Conclusions}

In conclusion, the results indicated that repeated oral health education comprising lecturing with interactive talk, demonstration and supervised tooth brushing methods at eight weekly intervals for 1 year was found to be effective in promoting and sustaining correct knowledge and behavior among school children.

\section{Supplementary information}

The online version contains supplementary material available at https://doi. org/10.1186/s12903-020-01368-0.

Additional file 1. Table S1. Scoring system for knowledge questions on oral health. Table S2. Scoring system for behavioral questions on oral health. Table S3. Operational definitions for the variables in the study.

\section{Abbreviations}

SPSS: Statistical Package for Social Science; OHE: Oral health education; vs: Versus.

\section{Acknowledgements}

We would like to mention our heartfelt thanks to the Township Medical Officer and Township Educational Officer in Magway Township, Magway Region, Myanmar for their kind permission to conduct this study and school children who actively participated. We also thank Prof. Nay Soe Maung, Rector (retired), University of Public Health, Yangon (Myanmar), Prof. Khay Mar Mya, Rector (retired), University of Public Health, Yangon (Myanmar), Dr. Soe Min Naing, Associate Professor, Department of Preventive and Social Medicine, University of Medicine, Magway (Myanmar) for their kind assistance and advice.

\section{Author's contributions}

KKS is Principal Investigator as well as first author and developed research protocol, led the research team in data collection, performed data management and report writing. She is also a corresponding author of this original research article. AKS is the second author and observed the tooth brushing method of the school children with the checklist and issued the results. SHA is the third author and gave the advice to conduct the present study and helped in the literature search. HZS is the fourth author and gave guidance and constructive criticism throughout the study. All authors read and approved the final manuscript.

\section{Funding}

The author (s) received no specific funding for this research project.

\section{Availability of data and materials}

Data are available upon request by coauthors and reviewers.

\section{Ethics approval and consent to participate}

Ethical clearance was obtained from the Institutional Review Board of the University of Public Health, Yangon, Myanmar. Written informed consent was obtained from the caregivers, and verbal consent was obtained from the school principal and class teachers. Written informed assent was obtained from all participant school children.

\section{Consent to publish}

Not applicable.

\section{Competing interests}

The authors declare that there is no competing interest among them.

\section{Author details}

${ }^{1}$ Department of Preventive and Social Medicine, Uiversity of Medicine, Magway, Myanmar. ${ }^{2}$ Maxillo-Facial Department, Teaching Hospital, Magway, Myanmar. ${ }^{3}$ Department of Preventive and Community Dentistry, University of Dental Medicine, Yangon, Myanmar. ${ }^{4}$ University of Community Health, Magway, Myanmar.

Received: 19 January 2020 Accepted: 15 December 2020

Published online: 02 January 2021

\section{References}

1. Peres MA, Macpherson LMD, Weyant RJ, Daly B, Venturelli R, Mathur MR, Listl S, Celeste RK, Guarnizo-Herreno CC, Kearns C, Benzian H, Allison P, Watt RG. Oral diseases: a global public health challenge. Lancet. 2019;394:249-60.

2. Martino S. Oral health behavioral and social intervention research concepts and methods. J Public Health Dent. 2011;71(Suppl 01):S2-6.

3. Trivedi H, Sharma S, Kumar Sharma V, Gupta ND. Behavioral factors and periodontal diseases. Eur J Pharm Med Res. 2016;3(Suppl 7):207-13.

4. World Health Organization: WHO information series on school health: Oral health promotion through schools. 2000.

5. Petersen PE. The World Oral Health Report 2003: continuous improvement of oral health in the 21 st century-The approach of the WHO Global Oral Health Programme. Community Dent Oral Epidemiol. 2003;31(Suppl 1):3-23.

6. Ogawa H, Soe P, Myint B, Sein K, Kyaing MM, Maw KK, Oo HM, Murai M, Miyazaki $\mathrm{H}$. A pilot study of dental caries status in relation to knowledge, attitudes and practices in oral health in Myanmar. Asia Pac J Public Health. 2003;15(Suppl 2):111-7.

7. Chu CH, Chau AMH, Wong ZSW, Hui BSY, Lo ECM. Oral health status and behaviours of children in Myanmar: a pilot study in four villages in rural areas. Oral Health Prev Dent. 2012;10(Suppl 4):365-71.

8. Phyo AZZ, Chansatitporn N, Narksawat K. Oral health status and oral hygiene habits among children aged 12-13 years in Yangon, Myanmar. Southeast Asian J Trop Med Public Health. 2013:44(Suppl 6):1108-14.

9. Myint ZCK, Maung K, Aung SH, Soe KK. Effectiveness of oral health education on 12 year old school children in the selected townships of Yangon region in Myanmar. Master Thesis. University of Dental Medicine, Department of Preventive and Community Dentistry, Yangon. 2014.

10. Aung EE, Maung K, Zaitsu T, Kawaguchi Y. An overview of oral health situation and challenges in Myanmar. Asian J Res Med Med Sci. 2018;1(Suppl 1):1-10.

11. Mohamadkhah F, Shokravi FA, Karimy M, Faghihzadeh S. Effects of lecturing on selfcare oral health behaviors of elementary students. Med J Islam Repub Iran. 2014;28(Suppl 86):6.

12. Petersen PE, Peng B, Tai B, Bian Z, Fan M. Effect of a school-based oral health education programme in Wuchan City, Peoples Republic of China. Int Dent J. 2004;54:33-41.

13. Gholami M, Pakdaman A, Montazeri A, Jafari A, Virtanen Jl. Assessment of periodontal knowledge following a mass media oral health promotion campaign: a population-based study. BMC Oral Health. 2014;14:31.

14. Halawany HS, Al Badr A, Al Sadhan S, Al Balkhi M, Al-Maflehi N, Abraham NB, Jacob V, Al Sherif G. Effectiveness of oral health education intervention among female primary school children in Riyadh, Saudi Arabia. Saudi Dent J. 2018;30:190-6.

15. Haque SE, Rahman M, Itsuko K, Mutahara M, Kayako S, Tsutsumi A, Md Islam J, Md Mostofa G. Effect of a school-based oral health education in preventing untreated dental caries and increasing knowledge, attitude, and practices among adolescents in Bangladesh. BMC Oral Health. 2016;16:44. 
16. Friel S, Hope A, Kelleher C, Comer S, Sadlier D. Impact evaluation of an oral health intervention amongst primary school children in Ireland. Health Promot Int. 2002;17(Suppl 2):119-26.

17. Gauba A, Bal I, Jain A, Mittal H. School based oral health promotional intervention: effect on knowledge, practices and clinical oral health related parameters. Contemp Clin Dent. 2013;4(Suppl 4):493.

18. Åstrøm AN, Mashoto KO. Changes in oral health related knowledge, attitudes and behaviours following school based oral health education and atraumatic restorative treatment in rural Tanzania. Norsk Epidemiol. 2012;22(Suppl 1):21-30.

19. Angelopoulou MV, Kavvadia K, Taoufik K, Oulis CJ. Comparative clinical study testing the effectiveness of school based oral health education using experiential learning or traditional lecturing in 10 year-old children. BMC Oral Health. 2015;15(Suppl 1):51.

20. Nakre P, Harikiran A. Effectiveness of oral health education programs: a systematic review. J Int Soc Prev Community Dent. 2013;3(Suppl 2):103.

21. Geetha Priya PR, Asokan S, Janani RG, Kandaswamy D. Effectiveness of school dental health education on the oral health status and knowledge of children: a systematic review. Indian J Dent Res. 2019;30:437-49.
22. Shenoy RP Sequeira PS. Effectiveness of a school dental education program in improving oral health knowledge and oral hygiene practices and status of 12- to 13-year-old school children. Indian J Dent Res. 2010;21(Suppl 2):253-9.

23. Worthington HV, Hill KB, Mooney J, Hamilton FA, Blinkhorn AS. A cluster randomized controlled trial of a dental health education program for 10-year-old children. J Public Health Dent. 2001;61(Suppl 1):22-7.

24. Haleem A, Khan MK, Sufia S, Chaudhry S, Siddiqui MI, Khan AA. The role of repetition and reinforcement in school-based oral health education: a cluster randomized controlled trial. BMC Public Health. 2016;16(Suppl 2):2.

\section{Publisher's Note}

Springer Nature remains neutral with regard to jurisdictional claims in published maps and institutional affiliations.
Ready to submit your research? Choose BMC and benefit from:

- fast, convenient online submission

- thorough peer review by experienced researchers in your field

- rapid publication on acceptance

- support for research data, including large and complex data types

- gold Open Access which fosters wider collaboration and increased citations

- maximum visibility for your research: over $100 \mathrm{M}$ website views per year

At BMC, research is always in progress.

Learn more biomedcentral.com/submissions 